\title{
Leader
}

\section{The neuropathology of the vegetative state after head injury}

\author{
J Hume Adams, B Jennett, D R McLellan, L S Murray, D I Graham
}

University

Department of

Neuropathology,

Institute of

Neurological Sciences,

South Glasgow

University Hospitals

NHS Trust, 1345

Govan Road, Glasgow

G51 4TF, UK

J Hume Adams

D R McLellan

D I Graham

University

Department of

Neurosurgery

B Jennett

University

Department of

Medicine and

Therapeutics, Western

Infirmary, Glasgow

L S Murray

Correspondence to:

Professor Graham.

email:

D.Graham@clinmed.gla.ac.uk

Accepted for publication 16 June 1999
The technologies of resuscitation and intensive care have reduced mortality after acute brain damage, but some of those rescued are left with permanent brain damage, the most severely affected being in a vegetative state. This was first defined by Jennett and Plum in $1972^{1}$ and consists of continuing unconsciousness with no evidence of awareness or cognitive responsiveness although there are periods of wakefulness with the eyes open. The patients breathe spontaneously and have a range of reflex activity but require tube feeding. Clinically, the condition is considered to be one in which the cerebral cortex seems no longer to be functioning but with the brain stem relatively intact. Some $40-50 \%$ of patients who are vegetative after an acute brain damage have sustained a head injury, the rest having mostly suffered hypoxic-ischaemic brain damage (reviewed by Jennett ${ }^{2}$ ). Some $6-14 \%$ of patients admitted with a severe head injury are in a vegetative state one month later. ${ }^{2}$ Analysis by the Multi-Society Task Force (1994) of over 700 published cases of patients in a vegetative state one month after an acute insult ${ }^{3}$ found that some of these patients recovered consciousness over the next few months, this being more common after traumatic than non-traumatic damage. It concluded that the vegetative state should not be declared permanent until 12 months after a head injury, a view endorsed by the Royal College of Physicians. ${ }^{4}$

The neuropathology of the vegetative state has been reviewed by Kinney and Samuel, ${ }^{5}$ but there have been many fewer detailed reports of the lesions after traumatic than after nontraumatic insults. We report here the findings in a series of 35 cases considered vegetative until the time of their deaths a month or more after head injury. They are drawn from a database of over 1300 cases of fatal blunt head injury covering the period 1968-1998 held in the department of neuropathology in the Institute of Neurological Sciences, Southern General Hospital, Glasgow and used in many of our previous publications. In a preliminary study of 18 patients surviving at least 30 days in vegetative state after head injury, McLellan et al identified diffuse axonal injury, extensive hypoxic damage in the neocortex, and secondary damage to the brain stem as the principal neuropathological bases of the vegetative state. ${ }^{6}$ A particular problem facing forensic pathologists, however, is the frequency with which there may be minimal or even absent macroscopic abnormalities in the brain, including even classic surface contusions, in a patient who has remained in the vegetative state after a head injury.

The present study of 35 patients includes the 18 reported earlier ${ }^{6}: 32$ were male and three female, with an age range of 7 to 75 years (median 38 years; 95\% confidence interval (CI) 31 to 45 years); the cause of injury in 17 was a road traffic accident, in nine an assault, in six a fall, and in three it was not known. Survival was less than three months in 11, between three and 12 months in 11, and longer than 12 months in 13 . It is possible that some of the cases studied who survived for less than a year might have shown a degree of recovery had they survived longer. The clinical records were assessed with particular reference to deterioration in the conscious level after a lucid interval, to determine whether or not the patient had talked after injury ${ }^{7}$; if the patient had talked but had not been completely rational the lucid interval was defined as having been partial.

All brains were fixed in 10\% formal saline for a minimum of three weeks before dissection, after which a full macroscopic and microscopic examination was undertaken in each case. ${ }^{8}$ Contusions were assessed semiquantitatively using the total contusion index. This index takes into account the depth and extent of surface contusions in various parts of the brain: zero means that there were no contusions, a contusion index in the twenties indicates moderately severe contusions, while one of more than 37 indicates severe contusions. ${ }^{9}$ Diffuse axonal injury was graded as described previously, ${ }^{1011}$ and in this series was always of the more severe grades - either grade 2 with a focal lesion in the corpus callosum or grade 3 with a similar lesion also in the dorsolateral sector of the rostral brainstem. The focal lesions that are not apparent macroscopically are not difficult to identify on microscopic examination, although it may be necessary to examine several levels of the corpus callosum. Shortly after the injury, the focal lesions are typically rarefied and may be haemorrhagic. By a month after injury the lesions are intensely cellular as a result of astrocytosis and microglial hyperplasia, often with the formation of lipid containing phagocytes. They are also well 
Table 1 Summary of principal features of 35 patients in vegetative state after head injury

\begin{tabular}{|c|c|c|}
\hline & Total $(n=35)$ & With DAI $(n=25)$ \\
\hline \multicolumn{3}{|l|}{ Lucid interval (n) } \\
\hline Absent & 30 & 24 \\
\hline Partial & 2 & 0 \\
\hline Total & 1 & 0 \\
\hline Not known & 2 & 1 \\
\hline \multicolumn{3}{|l|}{ Age (years) } \\
\hline Range & 7 to 75 & 7 to 75 \\
\hline Median & 38 (CI 31 to 45$)$ & $34(\mathrm{CI} 28$ to 44$)$ \\
\hline Sex & $32 \mathrm{M}, 3 \mathrm{~F}$ & $22 \mathrm{M}, 3 \mathrm{~F}$ \\
\hline \multicolumn{3}{|l|}{ Cause of injury } \\
\hline RTA & $17(49 \%)$ & $13(52 \%)$ \\
\hline Assault & $9(26 \%)$ & $7(28 \%)$ \\
\hline Fall & $6(17 \%)$ & $3(13 \%)$ \\
\hline Not known & $3(9 \%)$ & $2(7 \%)$ \\
\hline \multicolumn{3}{|l|}{ Survival (months) } \\
\hline Range & 1 to 102 & 1 to 102 \\
\hline Median & $9(\mathrm{CI} 6.5$ to 19$)$ & $9(\mathrm{CI} 6$ to 19.5$)$ \\
\hline Fracture of skull & $12(34 \%)$ & $7(28 \%)$ \\
\hline \multicolumn{3}{|l|}{ Total contusion index } \\
\hline Range & 0 to 21 & 0 to 21 \\
\hline Median & $4(\mathrm{CI} 3.5$ to 9$)$ & $3(\mathrm{CI} 2$ to 5$)$ \\
\hline DAI (grades 2 and 3) & $25(71 \%)$ & $25(100 \%)$ \\
\hline Intracranial haematoma & $9(26 \%)$ & $2(8 \%)$ \\
\hline Ischaemic damage (moderate and severe) & $15(43 \%)$ & $6(24 \%)$ \\
\hline \multicolumn{3}{|l|}{ Thalamic damage } \\
\hline Diffuse & $25(71 \%)$ & $18(72 \%)$ \\
\hline Focal & $3(9 \%)$ & 0 \\
\hline Raised ICP & $25(71 \%)$ & $15(60 \%)$ \\
\hline Damage to brain stem $2^{\circ}$ to high ICP & $5(14 \%)$ & $1(4 \%)$ \\
\hline \multicolumn{3}{|l|}{ Brain weight $(\mathrm{g})$} \\
\hline $\mathrm{R}$ ange & 670 to 1650 & 1020 to 1650 \\
\hline Median & 1270 (CI 1230 to 1360 ) & $1270($ CI 1225 to 1380$)$ \\
\hline Hydrocephalus & $27(77 \%)$ & $19(76 \%)$ \\
\hline
\end{tabular}

CI, 95\% confidence interval; DAI, diffuse axonal injury; F, female; ICP, intracranial pressure; $M$, male; RTA, road traffic accident; $2^{\circ}$, secondary.

circumscribed and lacking in myelin. With the passage of time, they become less cellular and somewhat shrunken, microcystic spaces may appear, and there are frequently some residual haemosiderin containing macrophages. Of the 10 cases classified as not having the severe grades of diffuse axonal injury (that is, grades 2 and 3), there were three in which there was microscopical evidence in the form of small clusters of microglia in white matter, consistent with the least severe grade (grade 1). It has already been established that failure to make a good recovery from a head injury may be attributed to this type of brain damage. ${ }^{12}$ The severity of ischaemic brain damage-largely in the neocortex - was also graded. The damage was classified as being severe when the lesions were diffuse, multifocal, or large infarcts in the distributions of arterial territories, and moderate when they were limited to the arterial boundary zones, singly or in combination with subtotal infarction in the distribution of the cerebral arteries. ${ }^{13}$ Only haematomas thought to be sufficiently large to act as significant intracranial expanding lesions (more than 35 $\mathrm{ml}$ ) were recorded, but two had not been evacuated surgically. Thus a thin film of blood in the subdural space or small intracerebral haemorrhagic lesions were not recorded as haematomas. The criterion of pressure necrosis in one or both parahippocampal gyri was used as evidence that the intracranial pressure had been high during life as a result of a supratentorial expanding lesion. ${ }^{14}$

Table 1 summarises the principal features in the total series of 35 cases and in the 25 in whom diffuse axonal injury was present. A common structural abnormality was diffuse axonal injury $(71 \%)$. The cases with diffuse axonal injury had a low incidence of fracture of the skull $(28 \%)$, an intracranial haematoma $(8 \%)$, raised intracranial pressure $(60 \%)$, and secondary damage in the brain stem $(4 \%)$ : all of these lesions are known to be less common in patients with diffuse axonal injury than in those with other types of traumatic brain damage. ${ }^{10}$ It also accounts for the low total contusion index (0-21): only one of the diffuse axonal injury cases had moderately severe contusions (contusion index 21), while in eight cases contusions were entirely lacking.

Another common abnormality in the 35 cases was ischaemic brain damage $(43 \%)$. This was often diffuse or concentrated in arterial boundary zones, being indicative of a global rather than a focal reduction of cerebral blood flow.

The thalamus was abnormal in $28(80 \%)$ of the 35 patients. In 25 the thalamus was diffusely abnormal and occasionally shrunken to the naked eye. In 18 of these 25 cases, the changes in the thalamus were associated with diffuse axonal injury, and in the remaining seven there was moderate or severe ischaemic brain damage. The mechanism of diffuse thalamic degeneration differs according to whether it reflects diffuse axonal injury or ischaemia. In diffuse axonal injury, retrograde thalamic degeneration occurs as a result of widespread axonal damage and takes some three months to develop. On the other hand, in thalamic damage associated with ischaemia there is diffuse thalamic neuronal loss as a result of hypoxia, and the changes are apparent a very short time after the episode. These differences are reflected in the gross and histological appearances of the thalamus. In diffuse axonal injury there is atrophy caused by shrinkage of nerve cells, and astrocytosis in the lateral and ventral nuclei with relative sparing of the anterior and dorsomedial nuclei, the pulvinar, the centro-median nuclei, and the lateral geniculate bodies. In contrast, in the cases in which the thalamic damage is attributable to ischaemia there is neuronal loss and astrocytosis in the anterior and dorsomedial nuclei with relative sparing of the lateral and ventral nuclei. The patterns in both types of case correspond to those described in diffuse degeneration of the cerebral white matter in severe dementia after head injury ${ }^{15}$ and in long survival after cardiac arrest. ${ }^{16}{ }^{17}$ Of the 10 cases without diffuse axonal injury there was ischaemic brain damage in nine and an intracranial haematoma in seven, and in all of these 10 cases the thalamus was abnormal.

The relation between diffuse axonal injury, diffuse ischaemic damage in the neocortex, and damage to the thalamus, whether retrograde degenerative or ischaemic, in patients who are vegetative after head injury is evident. In this series of 35 cases the importance of both diffuse axonal injury $(71 \%)$ and diffuse damage to the thalamus $(74 \%)$ is clearly seen, and there were 18 patients $(51 \%)$ who had both diffuse axonal injury and damage to the thalamus. There were two patients in whom there was neither diffuse axonal injury nor extensive ischaemic damage in the neocortex, but who 
had lesions within the thalamus: in both, the thalamic damage was bilaterally focal and associated with the formation of tentorial herniae and infarction within the distribution of each posterior cerebral artery secondary to high intracranial pressure. ${ }^{18}$ In contrast there were no cases in which the vegetative state could be attributed solely to ischaemic damage in the neocortex. The 13 with neocortical ischaemic damage also had damage in the thalami, and six of the 13 cases with neocortical ischaemic damage also had diffuse axonal injury. There were seven vegetative patients in whom thalamic damage was not present, six of whom survived less than three months and had diffuse damage to white matter caused by grade 3 diffuse axonal injury. In the remaining case, who had no thalamic damage and who lived for 18 months, there was also grade 3 diffuse axonal injury. The lower frequency of thalamic damage in the short term survivors was the only difference between the three survival cohorts.

Because of the essentially diffuse and multifocal types of brain damage that result in the vegetative state, the brains tend to become reduced in weight with the passage of time, while the ventricles enlarge. Further it is worth noting that with the exception of a higher frequency of bilateral damage to the thalami in those patients who lived longer than three months there were no noticeable differences between the cases grouped in each of the three survival periods.

The lesions in patients left vegetative after severe head injury are complex. The most consistent finding in Strich's studies was diffuse axonal injury with widespread degeneration of subcortical white matter. ${ }^{15} 19$ She maintained that these lesions were caused by shearing lesions sustained at the time of injury, but this was disputed by Jellinger et al and Peters et $a l^{2021}$ who considered that they reflected secondary effects of raised intracranial pressure and ischaemia. However, diffuse axonal injury has now been established as a common primary lesion both in $\operatorname{man}^{22}$ and in experimental animals, ${ }^{23}$ the result of the shearing forces that Strich had postulated. In its most severe form diffuse axonal injury is associated with macroscopic haemorrhagic tears in the corpus callosum and in the dorsolateral sectors of the rostral brainstem. However, the most important and consistent microscopic lesion in patients with diffuse axonal injury is widely distributed damage to axons. It is now possible by high quality computed tomography or magnetic resonance imaging in the acute stage after injury to detect or infer the various types of lesion associated with diffuse axonal injury. ${ }^{24} 25$

In three of the 35 cases there had been a partial or a total lucid interval: in two of the three (one partial and one total) the patient had developed an intracranial haematoma that required evacuation and in the other (total) the patient developed cardiorespiratory arrest soon after an apparently trivial head injury.

We have also studied the brains of patients who were very severely disabled at the time of death. We shall report these elsewhere but would note that there was considerable overlap with the findings in those who were vegetative until death. The main differences were that diffuse axonal injury and thalamic lesions were less common and evacuated intracranial haematomas more common than in the vegetative patients.

This study has further emphasised that the structural basis of the vegetative state can only be defined post mortem if the brain is properly fixed before dissection and appropriate histological studies are undertaken. Only then can the amount and distribution of diffuse axonal injury and damage caused by ischaemia or raised intracranial pressure be established and their contribution to the vegetative state determined.

1 Jennett B, Plum F. The persistent vegetative state: a syndrome in search of a name. Lancet 1972;1:734-7.

2 Jennett B. A quarter century of the vegetative state: an international perspective. F Head Trauma Rehabil 1997;12:1-12.

3 The Multi-Society Task Force on PVS. Medical aspects of the persistent vegetative state. N Engl F Med 1994;330: 1572-9.

4 Royal College of Physicians Working Party. The permanent vegetative state. F R Coll Physicians Lond 1996;30:119-21.

5 Kinney HC, Samuel MA. Neuropathology of the persistent vegetative state-a review. F Neuropathol Exp Neurol 1994;53:548-58.

6 McLellan DR, Adams JH, Graham DI, et al. In: Papo I, Cohadon F, Massaroti M, eds. Le coma traumatique. Padova: Liviana Editrice, 1986:165-85.

7 Reilly PL, Graham DI, Adams JH, et al. Patients with head injury who talk and die. Lancet 1975;2:375-7.

8 Adams JH, Graham DI, Scott G, et al. Brain damage in nonmissile head injury. 7 Clin Pathol. 1980;33:1132-45.

9 Adams JH, Doyle D, Graham DI, et al. The contusion index: a reappraisal in man and experimental non-missile head injury. Neuropathol Appl Neurobiol 1985;11:299-308.

10 Adams JH, Doyle D, Ford I, et al. Diffuse axonal injury in head injury: definition, diagnosis and grading. Histopathology 1989;15:49-59.

11 Graham DI, Adams JH, Nicoll JAR, et al. The nature, distribution and causes of traumatic brain injury. Brain Pathol 1995;5:397-406.

12 Adams JH, Doyle D, Graham DI, et al. Microscopic diffuse axonal injury in cases of head injury. Med Sci Law 1985;25: 265-9.

13 Graham DI, Ford I, Adams JH, et al. Ischaemic brain damage is still common in fatal non-missile head injury. $\mathcal{F ~ N e u -}$ rol Neurosurg Psychiatry 1989;52:346-50.

14 Adams JH, Graham DI. The relationship between ventricular fluid pressure and the neuropathology of raised intracranial pressure. Neuropathol Appl Neurobiol 1976;2: 323-32.

15 Strich SJ. Diffuse degeneration of cerebral white matter and severe dementia following head injury. $\mathcal{F}$ Neurol Neurosurg Psychiatry 1956;19:163-85.

16 Brierley JB, Adams JH, Graham D, et al. Neocortical death after cardiac arrest. Lancet 1971;ii:560-5.

17 Cole G, Cowie VA. Long survival after cardiac arrest: case report and neuropathological findings. Clin Neuropathol 1987;6:104-5.

18 Graham DI, Lawrence AE, Adams JH, et al. Brain damage in fatal non-missile head injury secondary to a high intracranial pressure. Neuropathol Appl Neurobiol 1987;13:209-

19 Strich SJ. Shearing of nerve fibres as a cause of brain damage due to head injury. Lancet 1961 ;ii:444-8.

20 Jellinger K. Pathology and pathogenesis of apallic syndrome following closed head injuries. In: Ore GD, Gerstenbrand $\mathrm{F}$, Lucking $\mathrm{CH}$, et al, eds. The apallic syndrome. Berlin: Springer 1977:88-103.

21 Peters G, Rothemund E. Neuropathology of the traumatic apallic syndrome. In: Ore GD, Gerstenbrand F, Lucking $\mathrm{CH}$, et al, eds. The apallic syndrome. Berlin: Springer 1977: 78-87.

22 Adams JH, Graham DI, Murray LS, et al. Diffuse axonal injury due to non-missile head injury in humans: an analysis of 45 cases. Ann Neurol 1982;12:557-63.

23 Gennarelli TA, Thibault LE, Adams JH, et al. Diffuse axonal injury and traumatic coma in the primate. Ann Neurol 1982;12:564-74.

24 Gean AD. Imaging of head trauma. New York: Raven Press, 1994:207-48.

25 Kampfl A, Schmutzhard E, Franz G, et al. Prediction of recovery from post-traumatic vegetative state with cerebral magnetic-resonance imaging. Lancet 1998;351:1763-7. 